\title{
CASE REPORT ON THE HUMAN INFECTION WITH TULAREMIA IN MYKOLAIV REGION, 2018
}

\author{
Zlenko O. B. ${ }^{1}$, Ignatenkov O. S. ${ }^{2}$, Vinokurova K. V. ${ }^{2}$, Gerilovych A. P. ${ }^{1}$ \\ ${ }^{1}$ National Scientific Center 'Institute of Experimental and Clinical Veterinary \\ Medicine', Kharkiv, Ukraine, e-mail: oksana.ceratium@gmail.com \\ ${ }^{2}$ Mykolaiv Regional Laboratory Center of the Ministry of Health of Ukraine, Mykolaiv, Ukraine
}

\begin{abstract}
Summary. The work aims to provide a study and report the case with a 47-year-old white man from urban-type settlement Oleksandrivka (Voznesensk District, Mykolaiv Region) diagnosed with pharyngitis, amygdalitis, polylymphoadenopathy, and buboadenitis caused by Francisella tularensis. The tularemia diagnosis in the patient was confirmed with agglutination test and western blot of patient's blood serum in dilutions 1:100 and 1:200 respectively. The additional surveillance study (rodents, ticks, and water samples) in the surrounding area of the patient's house showed positive results for $F$. tularensis in ticks in dilution $1: 160++++$
\end{abstract}

Keywords: Francisella tularensis, tularemia, zoonosis, ticks, Ukraine

Introduction. Tularemia is a zoonotic disease caused by a Gram-negative bacterium Francisella tularensis. The disease is widespread in the Northern Hemisphere and it is transmitted by contact with naturally infected animals (rodents or lagomorphs), inhalation, arthropod bites (ticks or deer flies), or ingestion of contaminated meat or water. Particularly active source of the F. tularensis is the common vole (Microtus arvalis). Cats are carriers of infection among pets. In total, over 100 species of animals can be infected with $F$. tularensis. Tularemia can be transmitted by 13 species of ticks belonging to 4 genera: Amblyomma, Dermacentor, Haemaphysalis, and Ixodes, from which the most epizootically significant for Ukraine are ticks of the genus Dermacentor. The transmission of tularemia from person to person has not been described. There is a high risk of human infection among hunters, farmers and country inhabitants as the infective dose is extremely low (less than 10 bacteria) (Petersen and Schriefer, 2005; Hopla, 1974; Sjöstedt, 2007; McLendon, Apicella and Allen, 2006; WHO, 2007; Oyston, Sjöstedt and Titball, 2004).

For the cultivation of F. tularensis, special nutrient media should be used such as FT, Chapin, and McCoy media containing cysteine. After $48 \mathrm{~h}$ of incubation at $37^{\circ} \mathrm{C}$ F. tularensis forms small and roundish colonies. The causative agent of tularemia is a bacterium that is slowly growing in culture and is extremely difficult to secrete from field samples (the rate of isolating from animal corpses is not higher $30 \%$ ). Therefore, the most commonly used methods for identifying $F$. tularensis are the detection of the pathogen genome (PCR) and antigens or antibodies to it (MA, ELISA). The results of these methods must be confirmed by western blot to avoid cross-reactions and false-positive results with other related bacteria (Brucella spp., Yersinia spp., etc.) (WHO, 2007; Bevanger, Maeland and Naess, 1988; Byström et al., 2005; Petersen et al., 2004; Schmitt et al., 2005).
The first official cases of tularemia in Ukraine were reported in the 1940s. They were related to the professional infection of fur and sugar workers. In 19481949 , tularemia deaths were reported in all regions of the country. In 1960, the incidence of tularemia declined sharply as a result of the natural foci identification and the implementation of special measures, namely: vaccination of people living in natural foci and reduction of rat populations. In the late 1980s and the 1990s, the epidemic activity of tularemia foci with an outbreak among people (approx. 200 cases of infection) was again registered in the steppe regions of Ukraine - Odesa and Mykolaiv, as well as constant foci activity was registered on Byriuchyi Island (Hightower et al., 2014; Rusev et al., 2005).

According to the official data of the Public Health Center of the Ministry of Health of Ukraine and Regional Laboratory Centers, at present, outbreaks of tularemia among people usually occur in the form of several isolated cases a year, with the onset of the disease in mild and medium forms, often with the buboes formation. The last case of human infection with tularemia in Ukraine was registered in March 2019 in the Okhtyrka District (Sumy Region). The vaccination against tularemia is not currently carried out in Ukraine.

The case. A 47-year-old white man from urban-type settlement Oleksandrivka (Voznesensk District, Mykolaiv Region) appealed to a traumatologist on 02.04.2018 because of a domestic swine bite that was held in his own small private swine household.

After the first aid of the traumatologist, on 06.04.2018 the patient visited an otorhinolaryngologist, who diagnosed pharyngitis.

On 12.04.2018 the patient was admitted to the Neurological department of the Voznesensk Central Regional Hospital. The diagnosis was changed to degenerative-dystrophic lesions of the spine, polylymphoadenopathy, amygdalitis. 
Three weeks later, on 27.04.2018, the patient appealed to the infectious disease doctor who changed the diagnosis to herpesvirus infection, polyadenopathy.

After the appearance of a bubo seven days later the diagnosis was changed to bubonadenitis, and it was started with blood tests for $F$. tularensis.

Materials and methods. Blood serum of the patient was taken in the Voznesensk Central Regional Hospital and sent to the Mykolaiv Regional Laboratory Center of the Ministry of Health of Ukraine. It was examined for F. tularensis antibodies using commercial agglutination test kit according to the manufacturer protocol ('Microgen', Russian Federation).

One aliquot of the sample was inactivated in water bath at $60^{\circ} \mathrm{C}$ for an hour and sent to the National Scientific Center 'Institute of Experimental and Clinical Veterinary Medicine' (Kharkiv), where it was studied for F. tularensis antibodies with western blot: invitrogen gel loading buffer ('Thermo Scientific', USA) was added into $150 \mu \mathrm{l}$ of F. tularensis LPS (concentration $2.5 \mu \mathrm{g} / \mu \mathrm{l}$ ). The mixture was boiled for $5 \mathrm{~min}$, cooled down on ice for 1-2 min, and applied into polyacrylamide gel. Run vertical electrophoresis in western blot electrophoresis buffer at $180-200$ V until LPS are separated. Assemble blotting sandwich with nitrocellulose membrane and provide blotting in pre-cooled transfer buffer with refrigerant for $1 \mathrm{~h} 15 \mathrm{~min}$ at $100 \mathrm{~V}$. The membrane was blocked in PBST with $5 \%$ skimmed milk for $1 \mathrm{~h}$ at $18-25^{\circ} \mathrm{C}$ or overnight at $4^{\circ} \mathrm{C}$. Then, the membrane was incubated with sample diluted 1:200 in PBST with 2\% rabbit serum ('BioWest', USA) for $1 \mathrm{~h}$ on a rocking plate. The membrane was washed 3 times with PBST. Then, the membrane was incubated with Mouse-anti-Human IgG Secondary HRPcoupled antibodies ('Invitrogen', USA) diluted 1:2,000 for $45 \mathrm{~min}$ at rocking plate. The membrane was washed 3 times with PBST. Then, membrane was incubated for 10 min in the dark with TMB SeramunBlau precipitate solution ('Seramun Diagnostica', Germany). The reaction was stopped by washing $1-2 \times$ with $\mathrm{H}_{2} 0$ and the membrane was left to dry.

The additional surveillance study (rodents, ticks, and water samples) in the surrounding area of the patient's house carried out using commercial agglutination test kit according to the manufacturer protocol ('Microgen', Russian Federation).

Results. The agglutination test approved the diagnosis 'tularemia' in the patient in sample dilution 1:100. The western blot approved the diagnosis in sample dilution 1:200 (Fig.).

In addition, positive results for F. tularensis in ticks in dilution 1:160++++ were obtained.

Discussion. Voznesensk District of Mykolaiv Region is an endemic territory of tularemia occurrence. F. tularensis was isolated there from small mammals in the 1990s (Hightower et al., 2005).

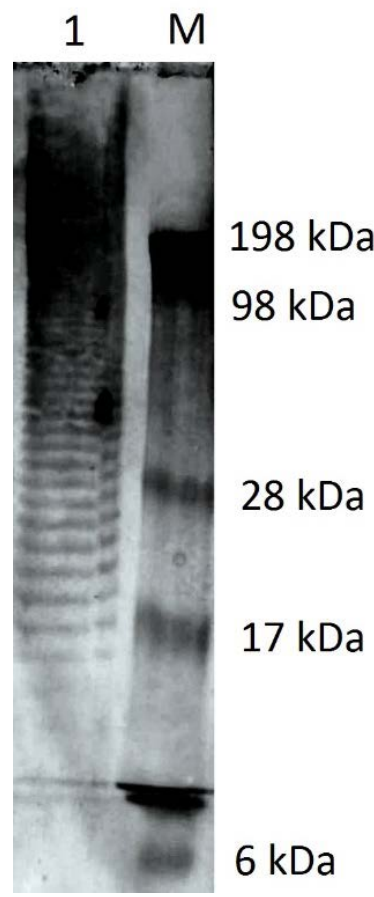

Figure. The western blot result of the patient serum: 1 - blood serum, $\mathrm{M}$ - protein weight marker Invitrogen SeeBlue Plus 2 ('Thermo Scientific', USA). The result considered as positive, when the LPS pattern is present in range of 15-98 kDA (Schmitt et al., 2005)

Despite the rare findings of $F$. tularensis in this district, it is known, that the outbreaks of tularemia may occur annually within 5 years, and may also be absent for more than a decade. Usually, after a long lapse, the first case of a new outbreak appears, the disease may be forgotten and not easily diagnosed (WHO, 2007). This thesis is clearly demonstrated in the case report: the diagnosis staging for the patient took the whole month and was done correctly only after the bubo appearance, when the illness became severe. For this reason, it is important to provide routine monitoring of regions for tularemia foci and make the results widely available, especially among physicians, to make diagnosis staging faster.

Conclusions. The tularemia diagnosis in the 47-yearold patient with pharyngitis, amygdalitis, polylymphoadenopathy, and buboadenitis from urbantype settlement Oleksandrivka (Voznesensk District, Mykolaiv Region) was confirmed with agglutination test and western blot of blood serum in dilutions 1:100 and 1:200 respectively.

The additional surveillance study (rodents, ticks, and water samples) in the surrounding area of the patient's house showed positive agglutination test results for F. tularensis in ticks in dilution 1:160++++.

Acknowledgments. The research was funded by the German Federal Foreign Office (project No. 16.9072.6007.04 'Ukrainian-German Biosecurity Initiative on Zoonosis Risk Management at the EU External Borders'). 


\section{References}

Bevanger, L., Maeland, J. A. and Naess, A. I. (1988) 'Agglutinins and antibodies to Francisella tularensis outer membrane antigens in the early diagnosis of disease during an outbreak of Tularemia', Journal of Clinical Microbiology, 26(3), pp. 433-437. doi: 10.1128/JCM.26.3.433-437.1988.

Byström, M., Böcher, S., Magnusson, A., Prag, J. and Johansson, A. (2005) 'Tularemia in Denmark: Identification of a Francisella tularensis subsp. holarctica strain by real-time PCR and high-resolution typing by multiple-locus variable-number tandem repeat analysis', Journal of Clinical Microbiology, 43(10), pp. 5355-5358. doi: 10.1128/JCM.43.10.5355-5358.2005.

Hightower, J., Kracalik, I. T., Vydayko, N., Goodin, D., Glass, G. and Blackburn, J. K. (2014) 'Historical distribution and host-vector diversity of Francisella tularensis, the causative agent of Tularemia, in Ukraine', Parasites \& Vectors, 7(1), p. 453. doi: 10.1186/s13071-014-0453-2.

Hopla, C. E. (1974) 'The ecology of Tularemia', Advances in Veterinary Science and Comparative Medicine, 18, pp. 25-53. PMID: 4419176.

McLendon, M. K., Apicella, M. A. and Allen, L.-A. H. (2006) 'Francisella tularensis: Taxonomy, genetics, and immunopathogenesis of a potential agent of biowarfare', Annual Review of Microbiology, 60(1), pp. 167-185. doi: 10.1146/ annurev.micro.60.080805.142126.

Oyston, P. C. F., Sjöstedt, A. and Titball, R. W. (2004) 'Tularemia: Bioterrorism defence renews interest in Francisella tularensis', Nature Reviews Microbiology, 2(12), pp. 967-979. doi: 10.1038/nrmicro1045.
Petersen, J. M. and Schriefer, M. E. (2005) 'Tularemia: Emergence/re-emergence', Veterinary Research, 36(3), pp. 455467. doi: 10.1051/vetres:2005006.

Petersen, J. M., Schriefer, M. E., Gage, K. L., Montenieri, J. A., Carter, L. G., Stanley, M. and Chu, M. C. (2004) 'Methods for enhanced culture recovery of Francisella tularensis', Applied and Environmental Microbiology, 70(6), pp. 3733-3735. doi: 10.1128/ AEM.70.6.3733-3735.2004.

Rusev, I. T., Mogilevskiy, L. Ya., Boshchenko, Yu. A. and Zakusilo, V. N. (2005) 'Biocenotic features of natural foci of Tularemia in the steppe zone of Ukraine' [Biotsenoticheskie osobennosti prirodnykh ochagov tulyaremii stepnoy zony Ukrainy], Bulletin of Sumy State University. Medicine Series [Visnyk Sumskoho derzhavnoho universytetu. Seriia Medytsyna], 7, pp. 25-35. Available at: https://essuir.sumdu.edu.ua/handle/ 123456789/10811. [in Russian].

Schmitt, P., Splettstösser, W., Porsch-Özcürümez, M., Finke, E.-J. and Grunow, R. (2005) 'A novel screening ELISA and a confirmatory western blot useful for diagnosis and epidemiological studies of Tularemia, Epidemiology and Infection, 133(4), pp. 759-766. doi: 10.1017/ S0950268805003742.

Sjöstedt, A. (2007) 'Tularemia: History, epidemiology, pathogen physiology, and clinical manifestations', Annals of the New York Academy of Sciences, 1105(1), pp. 1-29. doi: 10.1196/ annals.1409.009.

WHO (World Health Organisation) (2007) WHO Guidelines on Tularaemia. Geneva: WHO. Available at: https://apps.who. int/iris/handle/10665/43793. 